\title{
Level of Health Extension Service Utilization and Associated Factors Among Community of Merti Woreda Arsi Zone, Oromia Regional State, Ethiopia
}

\author{
Mitiku Uma Sinki ${ }^{1}$, Hailu Fikadu ${ }^{2,}$, , Shimelis Adugna ${ }^{3}$, Roza Amdemichael ${ }^{4}$, Shimelis Mekit ${ }^{5}$, \\ Mesfin Tafa ${ }^{2}$ \\ ${ }^{1}$ Public Health, Arsi Zone Health Office, Assela, Ethiopia \\ ${ }^{2}$ Public Health Department, Arsi University, Assela, Ethiopia \\ ${ }^{3}$ Medical Labratory Department, Arsi University, Asseala, Ethiopia \\ ${ }^{4}$ Midwifery Department, Arsi University, Assela, Ethiopia \\ ${ }^{5}$ Pharmacy Department, Arsi University, Assela, Ethiopia \\ Email address: \\ hailufekadu18@yahoo.com (H. Fikadu) \\ ${ }^{*}$ Corresponding author
}

\section{To cite this article:}

Mitiku Uma Sinki, Hailu Fikadu, Shimelis Adugna, Roza Amdemichael, Shimelis Mekit, Mesfin Tafa. Level of Health Extension Service Utilization and Associated Factors Among Community of Merti Woreda Arsi Zone, Oromia Regional State, Ethiopia. Journal of Cancer Treatment and Research. Vol. 8, No. 3, 2020, pp. 51-59. doi: 10.11648/j.jctr.20200803.11

Received: August 4, 2020; Accepted: August 13, 2020; Published: August 31, 2020

\begin{abstract}
Introduction: To address health problem of the rural community, Ethiopia launched Health Extension Program in 2003. Mother and child have been facing different problems and due to poor access to modern health care facilities. Lack of effective demands to utilize the available service also has its own contribution to the problems. Objective: The aim of this study was to assess the status of Health Extension Service Utilization and Associated Factors among Community of Merti Woreda Arsi Zone, Oromia Regional State, Ethiopia. Methodology: Community based, quantitative cross-sectional study using structured questionnaires were carried out. A total of 604 households were selected from each kebeles through systematic sampling from random starting point from household registration book using a number between one and sampling interval. The data was entered to Epi Info version 7computer software and transferred to SPSS version 21 computer software programs. Descriptive statistics was done for each variables, bivariate analysis between dependent and independent variables was performed. Multivariate analysis was done to control for possible confounding variable finally P-Value $<$ 0.05 with CI was used as level of significance. Results: The level of community utilization of health extension service was $92.4 \%$. Even though the health extension service is high, the implementation is found to be low in some packages such as women's immunization service, delivery, postnatal care service, community conversation, and model family. Age, educational status, religion, language, and knowledge about health extension service were identified as the independent factors affecting community health extension services utilization. Further studies should be undertaken to determine the level and factors affecting utilization of health extension service from the perspective of health extension workers on a wider scale. Conclusion: The level of community utilization of health extension service has registered relatively higher results as compared to the previous studies. Age, educational status, religion, language, and knowledge about health extension service were identified as the independent factors affecting community health extension services utilization.
\end{abstract}

Keywords: Level, Health Extension, Utilization, Mersti Woreda

\section{Introduction}

\subsection{Background Information}

Ethiopia has been implementing the health extension program to improve primary health coverage at grass root level starting from 2003. Health extension program is an innovative community based program started in 2003 [1]. Under a massive nationwide driven, over 38,000 Health Extension workers (HEWs) deployed for 15000 health posts (with catchment area population of about 5000). The Health extension workers are bringing a basic health service to 
doorsteps of Ethiopia's large rural population, facilitating closer contact between health workers and community at large [2]. Health extension workers give services of health Extension program activities being at Health post in the center of each kebeles [3]. This can facilitate the achievement of health related millennium development goals in particular and other Millennium Development Goal (MDGs) in general [4].

The implementation of HEP involves deployment of two trained and salaried female HEWs at each kebeles. These health extension workers are posted to rural communities across Ethiopia, where they provide a better and more equitable access to health services for the poor, women, and children in a sustainable manner [5].

Under this program provides 16 different packages to reach the poor and address inequities and focusing on four areas of care: Disease Prevention and Control, Family Health, Hygiene and Environmental Sanitation, and Health Education and Communication. HEWs spend $75 \%$ of their time visiting families in their homes and performing outreach activities in the community. The remaining $25 \%$ is spent providing services at the health posts, including immunizations and injectable contraceptives, among others. To address strong community demands for basic curative care, HEWs are trained to provide first aid and to treat malaria, dysentery, intestinal parasites and other ailments. In addition, they refer cases to the nearest health center when care that is more complicated is needed [6].

Al most all kebeles has a health post that serves 5,000 peoplein average and functions as an operational center for a health extension worker. 5 health posts and one satellite health center work jointly and for the Primary Health Care Unit (PHCU) that serves 25,000 people [7]. Most of the time, the health post was closed; they have not known time at which they give services at the health post therefore most of them returned back to home without getting the required services. Similarly, HEWs are working in one class given by kebele because the construction of health post was not completed yet even in place where health post construction was completed, recommended supply were not secured [8]. The basic philosophy of the HEP is to transfer ownership of and responsibility for maintaining their own health to individual households by transferring health knowledge and skills to households. Health extension workers spend 75 percent of their time visiting families in their homes and performing outreach activities in the community [9].

\subsection{Statement of the Problem}

Several efforts have made over the last 30 years to improve human health throughout the world. Among the global commitments, the Millennium Development Goals put specific targets to reduce under-5 child mortality rate by twothirds and maternal mortality ratio by three-fourths between 1990 and 2015 [10]. However, despite heightened awareness and efforts by international and national governments around the world, maternal and child health have improved very slightly. Currently more than half a million maternal deaths occur annually worldwide [11] and nearly 2 million children die each year from vaccine preventable diseases and about 26 million children are inadequately protected. Health systems in Sub-Saharan African countries often suffer from weak infrastructure, lack of human resources, and poor supply systems. Access to health services is particularly low in rural areas, where the majority of the population still lives. As in other developing countries, Ethiopian children and mothers have been facing several health problems due to poor access to modern health care facilities and due to lack of effective demand to utilize the available ones. Consequently, Ethiopia's records on child and maternal health have remained rather dismal for many decades. With only $26 \%$ and $5 \%$ of the pregnant women getting antenatal care and delivery care by trained health professional, respectively, Ethiopia has one of the lowest maternal health services in sub-Saharan Africa [12]. Throughout the 1990s, poor nutritional status, infections, and a high fertility rate, together with low levels of access to basic health services in Ethiopia, contributed to one of the highest maternal and child mortality ratios in the world. In 2005, almost all births took place at home, with only 6 percent of women delivering in a clinic or hospital. Major causes of morbidity and mortality for children under-5 years of age were preventable. Extrapolations from the, 2005 Demographic and Health Survey showed malnutrition to be the underlying cause of more than half of deaths of children under five [13]. In 2005, only $1 \%$ of households owned a bed net, of which less than $18 \%$ were insecticide treated [12]. Study conducted in Abuna Gidaberet West Shoa Zone of Oromia regional state shows that more than two third of study participant 314 (39\%) utilized health extension services of which 297 (36.8\%) of the respondents uses latrine construction and use. Antenatal care services, delivery services and postnatal care were services less utilized by 38 (4.7\%), $23(2.9 \%)$ and $36(4.5 \%)$ of study participants, respectively (8) and only $7 \%$ of all mothers received a postnatal visit within the first two days. Lack of progress in NMR reduction may be explained by the high proportion of birth taking place at home and low availability of newborn care and poor care seeking practices [14].

To improve the above-mentioned and other related health problems, Ethiopia has launched an innovative communitybased Health Services Extension Program (HSEP) in 2003 at national level. The primary purpose of the HSEP is to improve access and utilization of preventive, promotive, and basic curative services especially to children and mothers in the country by creating opportunities to enable households to exercise a health practice and living healthy through comprehensive, interrelated, economically and technically feasible health interventions [15]. To overcome the earlier-mentioned and other related health problems, Ethiopia has launched an innovative community-based Health Services Extension Program (HSEP) in 2003 at national level. Consequently, significant efforts has made in 
expanding health extension program to rural communities across Ethiopia. Even though there is progress in accelerating the health extension program to rural communities, the gap between the HES provision and community health extension service utilization is needed to be identified.

Since it has been in to implementation in 2003 up to now, there is a little evidence were there in some parts of the country and no evidence conducted on the level of health extension service utilization and associated factors in the study area. For this reason, little is known about status of health extension service utilization. Therefore, conducting the study on the status of health extension service utilization and associated factors is essential for developing strategies for awareness creation aimed to improve community health extension service utilization.

\subsection{Significance of the Study}

The findings of the study will helpful to explore the level of health extension service utilization and associated factors among community. Therefore, programmers, policy-makers, woreda health office, concerned non-governmental organizations more effectively address this problem by developing suitable interventions aimed at improving the utilization of health extension service depending on the find that have the study come up with in the woreda. It was also used as a stepping board for further studies.

\section{Objective}

\subsection{General Objective}

To assess the level of health extension service utilization and associated factors among community in Merti Woreda, Arsi Zone, Oromia Regional State, Ethiopia from January 01, 2016 to June 15, 2016.

\subsection{Specific Objectives}

1. To determine the level of health extension service utilization among community.

2. To identify factors associated with utilization of health extension services.

\section{Methods and Materials}

\subsection{Study Area}

The study was conducted in Merti Woreda, Arsi Zone, Oromia Regional State. The administrative town of this woreda Abomsa located 192 KM East of Addis Ababa. It has a total population of 117,224 of which $57,440(49 \%)$ are male and 59,784 (51\%) Female and one urban Kebele and 19 rural Kebele with the total 20 Kebeles. 19 health posts, $4 \mathrm{HCs}$ and 1 district Hospital serving the community. The woreda has also a total of 110 health workers with different profession serving the peoples in the above mentioned health facilities. All kebeles have 2 health extension workers in the community at large (Woreda health office, 2015).

\subsection{Study Design and Study Period}

Study Design and Study Period -A community based, quantitative cross-sectional study was carried out. The study was conducted from January 01, 2016 to June 15, 2016.

\subsection{Study Population}

Study population -All randomly selected heads of the households who were living in the selected kebeles of the woreda.

Inclusion criteria- All heads of the households age 18 years and above those who were heads of the households living for more than one year in the study kebele had been included.

\subsection{Sample Size and Sampling Procedure}

\subsubsection{Sample Size Determination}

A cross sectional quantitative study a single population proportion formula was employed to estimate the sample size: $\left.n=(Z \alpha / 2)^{2} \times P(1-p) / d^{2}\right]$. By taking the proportion $\%$, from other studies in other part of the country (8), the proportion was used to get the maximum sample size. Where

1) $n=$ estimated sample size

2) $\alpha=$ the risk of rejecting the null hypothesis $(0.05)$

3) $d=$ Degree of precision or margin of error $(0.05)$

4) $\mathrm{P}=$ Proportion taken from previous study $(0.25)$

5) Non-response rate $=10 \%$

6) $\mathrm{D}=$ design effect $=2$

$\mathrm{n}=(1.96)^{2} \times 0.25(1-0.25) /(0.05)^{2}=288$

$\mathrm{n}=288 * 2+10 \%(288)$

$\mathrm{n}=604$ Households

\subsubsection{Sampling Procedure}

The study was employed multistage sampling technique. Using simple random sampling, 6 kebeles were selected from 19 rural kebeles that were found in the woreda. After the selection of kebeles, the sample size was distributed to the 6 randomly selected kebeles proportional to the size of their households. A study household was selected from each kebeles through systematic sampling from random starting point from household registration book using a number between one and sampling interval. The subsequent households to be included in the study were identified through house-to-house visits, each time adding sampling interval to the pervious number. The household registration book for each kebele was obtained from health extension workers. The sampling interval of households in each kebeles was determined by dividing the total number of households to the allocated sample size. Revisit of two times is made in case where eligible respondents were not available by the time of the survey. In case were illegible subjects in the selected households where not available the nearest households were visited. 


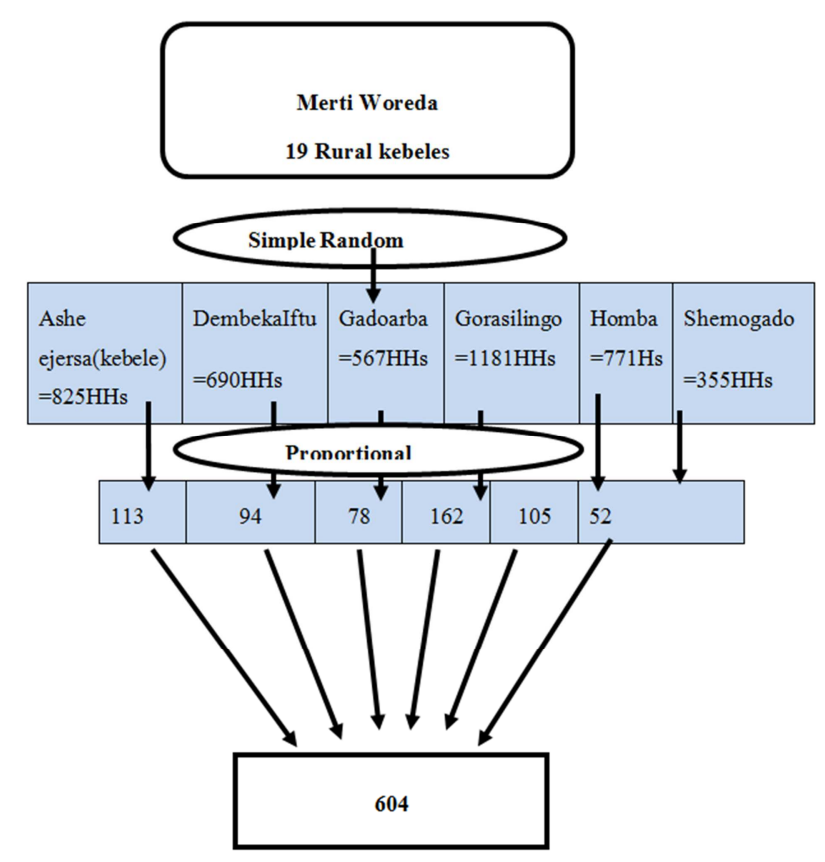

Figure 1. Sampling frame.

\subsection{Study Variables}

\subsubsection{Dependent Variable}

Health extension service utilization

\subsubsection{Independent Variables}

Socio demographic factors (Age, Sex, Marital status, Religion, Educational status, Ethinicity, occupation and family size)

Knowledge of community on health extension package

Community involvement/participation

Graduation of model family

\subsection{Operational Definition}

Knowledgeable of HEP: knowledge was measured based on respondent's ability to respond the questions related to health extension package. Respondent's score of below the mean were classified as having unsatisfactory knowledge and those who score above or equal to the mean were considered as having satisfactory knowledge on health extension package/services.

Health extension service utilization: Health extension service utilization was measured using respondent's utilization of selected health extension service (services given by HEWs at health post and outreach). Respondent's score above or equal to the mean were considered as utilized and respondent's score below the mean were classified as not utilized.

\subsection{Data Collection Procedures}

The data were collected by interviewing study participants using semi-structured questionnaire. The respondents for the questionnaires were head of the households. The questionnaire was first prepared in English after reviewing relevant literatures to include all the possible variables that address the objectives of the study. The questionnaire contains close-ended questions. The English versions of the questionnaire were translated in to Afan Oromo language in order to create a better understanding between the data collectors and the respondents. Consistency was checked by translating the Afan Oromo version back to English by both languages expert.

\subsection{Data Quality Assurance}

To ensure data quality, two days training was given to data collectors and supervisors to increase the reliability of the data collectors. During data collection, data collectors had been supervised on how they were administering questions and randomly visiting household by supervisors and the PI. Codes were given to the questionnaires and households during the data collection so that any identified errors would be traced back using the codes. Data collectors, supervisors and PI had rechecked the filled questionnaires for completeness on daily basis.

\subsection{Data Processing and Analysis}

The data were first checked manually for completeness and double entered to Epi Info version7 computer software. The entered data were transferred to SPSS version 21 computer software programs for further processing. The data were then cleaned by visualizing, calculating frequencies and sorting. A correction was done according to the original data. Finally, univariate analyses were done using frequency and percentage. A bivariate analysis between dependent and independent variables was performed.

Multivariate analysis was also be done to control for possible confounding variable by selecting only variable which show statistically significant association in bivariate analyses to identify independent predictor factors. During the analyses P-value and 95\% confidence interval (CI) for OR (odds ratio) were used in judging the significance of the associations and P-value less than 0.05 taken as significant association. The findings were presented by text and tables. Then, discussion, conclusion and recommendations were presented.

\subsection{Ethical Considerations}

The survey was conducted after the ethical and scientific clearance obtained from research ethical committee of Arsi University College of Health sciences. Official permission was obtained from Zonal and District health administrative offices. In turn, the Woreda Health Office had written a letter for study kebeles to get recognition and collaboration. Informed written and signed consent was obtained from respondents after explaining the objective of the study. They were informed that their participation was voluntary. Data were collected after assuring the confidential nature of response and consent was obtained from the study participants. 


\section{Results}

Out of the total 604 respondents, all questioners have been filled and returned, that mean the response rate was $100 \%$.

\subsection{Socio-demographic Characteristics of Respondents}

Among the total 604 study subjects, majority, 460 (76\%) of the respondents were female. The age of the study participants ranged from 19-70 years. More than one third $217(36 \%)$ of them have the age of 40 and above. One hundred thirteen (19\%) were between 25-29 years of age while 108 (18\%) were between 30-35 years.

Regarding their educational status, more than half of the respondents $342(56.6 \%)$ was illiterate. One hundred and seventy two $(28.5 \%)$ attended elementary school. One hundred thirty one (22\%) had a household income of 114-200 ETB. Respondents who have a family income of less than 70 ETB, 71-113 ETB, and above 401 ETB have a proportional number- $122(20 \%), 120(20 \%)$ and $118(20 \%)$ respectively. Concerning to family size of the respondents, nearly half of them 260 (43\%) had family size of 4-5 and 172 (28.5\%) had a family size of 5 and above.

The highest number of respondents 474 (78\%) were married in their marital status and 370 (61\%) were housewives by occupation. In case of religion near to half of the respondents were followers of Orthodox Christian 273 (45\%) and 212 (35\% were Muslims. In ethnicity Oromo 400 (66\%) and Amhara 203 (33.6\%) took the upper hand. Regarding language 445 (74\%) of the respondents were speakers of Afan Oromo and the rest 159 (26\%) were speakers of Amharic.

Table 1. Socio-demographic characteristics of respondents in Merti woreda, Arsi zone, Oromia regional state, Ethiopia, 2016.

\begin{tabular}{llll}
\hline Socio-demographic factors & $\begin{array}{l}\text { Frequency } \\
\text { (N=604) }\end{array}$ & $\begin{array}{l}\text { Percentage } \\
(\mathbf{\%})\end{array}$ \\
\hline Sex of respondents & Male & 144 & 24 \\
& Female & 460 & 76 \\
& $\leq 19$ & 23 & 3.8 \\
& $20-24$ & 72 & 11.9 \\
age category & $25-29$ & 113 & 18.7 \\
& $30-34$ & 108 & 17.9 \\
& $35-39$ & 71 & 11.8 \\
Educational level & Above 40 & 217 & 35.9 \\
of the respondents & Primary & 342 & 56.6 \\
(Binned) & Secondary & 49 & 8.1 \\
& above secondary & 8 & 28.5 \\
& $<=70$ & 122 & 5.5 \\
Family income of & $71-113$ & 120 & 1.3 \\
the respondents & $114-200$ & 131 & 20 \\
(Binned) & $201-400$ & 113 & 20 \\
& $401+$ & 118 & 19 \\
& 0 & 10 & 20 \\
family size & $1-3$ & 162 & 1.7 \\
& $4-5$ & 260 & 27 \\
& $5+$ & 172 & 28.5 \\
\hline
\end{tabular}

\begin{tabular}{llll}
\hline Socio-demographic factors & Single & $\begin{array}{l}\text { Frequency } \\
(\mathbf{N = 6 0 4 )}\end{array}$ & $\begin{array}{l}\text { Percentage } \\
\text { (\%) }\end{array}$ \\
\hline \multirow{3}{*}{$\begin{array}{l}\text { Marital status of } \\
\text { the respondents }\end{array}$} & Married & 40 & 5 \\
& Separated & 28 & 78 \\
& Divorced & 37 & 5 \\
& Widowed & 35 & 6 \\
Religion of the & Orthodox & 273 & 6 \\
respondents & Protestant & 48 & 45 \\
& Muslim & 212 & 8 \\
Ethnic group of the & Others & 71 & 35 \\
respondents & Oromo & 400 & 12 \\
& Amhara & 203 & 66.2 \\
Language of the & Others & 1 & 33.6 \\
respondents & Afan room & 445 & .2 \\
& Amharic & 159 & 74 \\
Job of the & Farmer & 152 & 26 \\
respondents & House wife & 370 & 25 \\
& Merchant & 46 & 61 \\
& Other & 36 & 6 \\
\hline
\end{tabular}

\subsection{Knowledge of Participants on Health Extension Package}

As shown in the table below, $501(83 \%)$ of the respondents reported that they know about Health extension service.

Concerning to environmental sanitation and hygiene, majority of the respondents 588 (97\%), 576 (95\%), $573(95 \%)$ and $525(87 \%)$ were reported that they were aware about use of clean water, health home environmental sanitation, latrine construction and use, and personal hygiene respectively. Regarding the family health package of HEP, majority of the respondents said that they have knowledge about family planning (84\%), nutrition (72\%), antenatal care (71\%), and immunization (66\%) respectively. The last broad part of HEP was also presented to respondents. Like the other packages discussed above, majority of the respondents found to be aware about TB prevention and control (83\%), malaria prevention and control (75\%), HIV/AIDS prevention and control (67\%), and STI prevention and control (60\%).

Table 2. knowledge of participants about health extension service in Merti woreda, Arsi zone, Oromia regional state, Ethiopia, 2016.

\begin{tabular}{|c|c|c|}
\hline Variables & $\begin{array}{l}\text { Frequency } \\
(\text { yes })(N=604)\end{array}$ & $\begin{array}{l}\text { Percentage } \\
(\%)\end{array}$ \\
\hline $\begin{array}{l}\text { Do you know about health extension } \\
\text { packages? }\end{array}$ & 501 & 83 \\
\hline Environmental sanitation and Hygiene & & \\
\hline Personal hygiene & 525 & 87 \\
\hline Health home environmental sanitation & 576 & 95 \\
\hline Latrine construction and usage & 573 & 95 \\
\hline Use of clean water & 588 & 97 \\
\hline \multicolumn{3}{|l|}{ Family health } \\
\hline Antenatal care & 430 & 71 \\
\hline Nutrition & 435 & 72 \\
\hline Immunization & 400 & 66 \\
\hline Family planning & 507 & 84 \\
\hline \multicolumn{3}{|l|}{ Disease prevention and control } \\
\hline HIV/AIDS prevention and control & 406 & 67 \\
\hline TB prevention and control & 501 & 83 \\
\hline Malaria Prevention and control & 454 & 75 \\
\hline STI prevention and control & 363 & 60 \\
\hline
\end{tabular}




\subsection{Community Participation in Planning Health Extension Program Activities}

As shown in table 4, both the community and household participation was low on construction and planning of health extension packages whereas high participation was manifested regarding community and household participation on the activities of health extension packages. Above half of the respondents reported that their households are not a participant on the construction (59.4\%) and planning (66.6\%) of health extension packages. Concerning to participation on HEP activities, the highest number of respondents said that their household (92\%) and the community as a general (79\%) participate on the activities of HEP.

Table 3. Community participation on HEP in Merti woreda, Arsi zone, Oromia regional state, Ethiopia, $2016(N=604)$.

\begin{tabular}{llll}
\hline & & Frequency & Percent \\
\hline Community participation in & No & 128 & 21 \\
HEP activities & Yes & 476 & 79 \\
House hold participation on & No & 50 & 8 \\
HEP activities & Yes & 554 & 92 \\
House hold participation & No & 402 & 67 \\
activities on HEP planning & Yes & 202 & 33 \\
House hold participation on & No & 359 & 59 \\
HEP construction & Yes & 245 & 41 \\
& Total & 604 & 100 \\
\hline
\end{tabular}

\subsection{Model Family Graduation Status of Participants}

As shown in table 5, the time length of training on model family was a little bit different. Most of the respondents 369 $(61 \%)$ had not been taking the training as a model family. Two hundred twenty fife $(37 \%)$ had been trained for three months and $10(1.7 \%)$ for 6 months. When we had seen graduation status of the respondents, more than half 350 $(58 \%)$ of them were not graduated as a model family and 254 $(42 \%)$ of them do not awarded certificate.

Table 4. Model family graduation in Merti woreda, Arsi zone, Oromia regional state, Ethiopia, 2016.

\begin{tabular}{llll}
\hline & & Frequency & Percent \\
\hline Model family graduation & No & 350 & 57.9 \\
status of the respondents & Yes & 254 & 42.1 \\
Duration of house hold & Total & 604 & 100 \\
respondents trained as & Three months & 225 & 37.3 \\
model family & Six months & 10 & 1.7 \\
Household respondents & No & 353 & 58.4 \\
awarded certificate & Yes & 251 & 41.6 \\
& Total & 604 & 100.0 \\
\hline
\end{tabular}

\subsection{Level of Health Extension Service Utilization}

As shown in table 5 of the total respondents, 558 (92.4\%) reported that they had utilized health extension services and $499(82.6 \%)$ said that they had visited by HE workers in the last six months. Community utilization of health extension service was measured using respondent's utilization of selected health extension services (services given by health extension workers at health post and outreach).

Specifically family planning 432 (71\%), child immunization service $544(90 \%)$, antenatal care service 578 (95.7\%), health education service 527 (87\%), treatment services 566 (93.7\%), latrine construction and use 583 (96.5\%), waste disposal $472(78.8 \%)$, clean home and environment $585(96.8 \%)$ were the most frequent services practiced by the respondents. On the other hand, women's immunization service 259 (42.8\%), delivery 233 (38.6\%), postnatal care service $193(32 \%)$, community conversation $122(20 \%)$, and model family $217(36 \%)$ were services less utilized by respondents.

Table 5. Level of health extension service utilization in Merti woreda, Arsi zone Oromia region, Ethiopia.

\begin{tabular}{lll}
\hline Variables & $\begin{array}{l}\text { Frequency } \\
\text { (yes) }(\mathbf{n = 6 0 4})\end{array}$ & $\begin{array}{l}\text { Percentage } \\
(\mathbf{\%})\end{array}$ \\
\hline Total utilization & 558 & 92.4 \\
Visit by HE worker in the last 6 months & 499 & 82.6 \\
Family planning care service & 432 & 71 \\
Child immunization service & 544 & 90 \\
Women's immunization service & 259 & 42.8 \\
Antenatal care service & 578 & 95.7 \\
Delivery & 233 & 38.6 \\
Postnatal care service & 193 & 31.9 \\
Health education & 527 & 87.2 \\
Treatments service4 & 566 & 93.7 \\
Latrine construction and use & 583 & 96.5 \\
Waste disposal & 472 & 78.8 \\
Community conversation & 122 & 20.2 \\
Clean home and environment & 585 & 96.8 \\
Model family & 217 & 35.9 \\
\hline
\end{tabular}

As shown in table 6, the result of the study revealed that: age, educational status, language, religion and knowledge of respondents on health extension service were found to be significantly associated with health extension service utilization as seen in chi square table. Variables that have $p$ value of $\leq .05$ were entered into multivariate logistic regression analysis.

Respondents who were in the age range of 35-49 were 2.17 times more likely to utilize health extension service when compared to those respondents who were in the age range of $15-24 \quad(\mathrm{AOR}=2.17 ; 95 \% \quad \mathrm{CI}=1.557,8.47)$. Respondents who attended primary educational were 1.82 times more likely to utilize health extension services when compared with those respondents whose educational status were illiterate $(\mathrm{AOR}=1.82 ; 95 \% \mathrm{CI}=1.506,6.58)$.

Regarding language of respondents, Amharic speaker respondents were 2.42 times more likely to utilize the health extension service as compared to those respondents who were speakers of Afan Oromo ( $\mathrm{AOR}=2.42 ; 95 \% \mathrm{CI}=.272,21.49)$. Muslim participants were.090 times less likely to utilize health extension services as compared to Orthodox Christian $(\mathrm{AOR}=.090 ; 95 \% \mathrm{CI}=.011,765)$. Similarly, participants who were labeled as "others" were.024 times less likely to utilize health extension services as compared to Orthodox Christian $(\mathrm{AOR}=.024 ; 95 \% \mathrm{CI}=.003, .216)$. Respondents who have a knowledge on health extension service were 5.33 times more likely to utilize health extension services when compared to those respondents who have not satisfactory knowledge $(\mathrm{AOR}=5.33 ; 95 \% \mathrm{CI}=2.15,13.23)$. 
Table 6. Multivariate logistic regression analysis of independent factors affecting health extension service utilization in Merti woreda, Arsi zone Oromia region, Ethiopia, 2016.

\begin{tabular}{|c|c|c|c|c|}
\hline \multirow{2}{*}{ Factors } & \multicolumn{2}{|c|}{ HEP utilization } & \multirow[b]{2}{*}{ COR $(95 \%$ CI) } & \multirow{2}{*}{ AOR (95\% CI) } \\
\hline & Utilized & Not utilized & & \\
\hline \multicolumn{5}{|l|}{ Age } \\
\hline $15-24 *$ & 87 & 8 & 1 & 1 \\
\hline $25-34$ & 205 & 16 & $1.18(.48,2.85)$ & $1.41(.360,5.54)$ \\
\hline $35-49$ & 210 & 6 & $3.20(1.08,9.55)^{* *}$ & $2.17(.557,8.47)^{* *}$ \\
\hline 50 and above & 56 & 16 & $.32(.12, .80)^{* *}$ & $.444(.098,2.01)$ \\
\hline \multicolumn{5}{|l|}{ Educational status } \\
\hline No education* & 309 & 33 & 1 & 1 \\
\hline Read and write & 42 & 7 & $.64(.27,1.1 .54)$ & $2.43(.753,7.87)$ \\
\hline Primary education & 166 & 6 & $2.95(1.21,7.20) * *$ & $1.82(.506,6.58)^{* *}$ \\
\hline \multicolumn{5}{|l|}{ Language } \\
\hline Afan Oromo* & 400 & 45 & 1 & 1 \\
\hline Amharic & 158 & 4 & $17.77(2.43,130.05)^{* *}$ & $2.42(1.272,21.49)^{* *}$ \\
\hline \multicolumn{5}{|l|}{ Religion } \\
\hline Orthodox * & 272 & 3 & 1 & 1 \\
\hline Protestant & 48 & 3 & - & - \\
\hline Muslim & 192 & 20 & $.035(.005, .265)^{* *}$ & $.090(.011, .765)^{* *}$ \\
\hline Others & 46 & 25 & $.007(.001, .051)^{* *}$ & $.024(.003, .216)^{* *}$ \\
\hline \multicolumn{5}{|c|}{ Knowledge about HEP } \\
\hline No $*$ & 82 & 20 & 1 & 1 \\
\hline Yes & 475 & 26 & $4.46(2.38,8.35)^{* *}$ & $5.33(2.15,13.23)^{* *}$ \\
\hline
\end{tabular}

\section{Discussion}

This was a community based cross-sectional study with the objective of the assessment of the utilization and associated factors of health extension services among community of Merti Woreda Arsi Zone, Oromia Regional State, Ethiopia. The study result revealed out of the total 604 respondents, $558(92.4 \%)$ had utilized health extension service. The result of the study shows that there is a big improvement on health extension service compared to previous studies. According to EDHS (2014), postnatal care service coverage was very low in Ethiopia by the year 2014 (19).

This result is higher compared to the result conducted in Akaki district, Ethiopia by the year 2012 that revealed as about $86.6 \%$ of respondents reported that they had been visiting at least monthly (35). The result was also significantly higher than the previous cross sectional studies conducted in Abuna Gindaberet District, Oromia Regional State, Ethiopia (36). This may be attributed to the time difference that there could be improvement in accessing and utilizing health extension service through time.

Regarding the specific packages of health extension service, family planning, child immunization service, antenatal care service, health education service, treatment services, latrine construction and use, waste disposal, clean home and environment found to be the most utilized services. However, women's immunization service, delivery, postnatal cares service, community conversation, and model family among the service utilized by few study participants.

Among the socio demographic factors, the key predictor for HEP utilization in this study was age of the respondents. That means utilization of HEP increased as age increased. This may be because of the exposer of respondents to more familiar and social responsibilities as their age increases.
Religion found to be the other factor that determines the utilization of health extension service. As shown in the result, Muslim participants were. 090 times less likely to utilize health extension services as compared to Orthodox Christian ( $\mathrm{AOR}=.090 ; 95 \% \mathrm{CI}=.011,765)$. Similarly, participants who were labeled as "others" were.024 times less likely to utilize health extension services as compared to Orthodox Christian ( $\mathrm{AOR}=.024 ; 95 \% \mathrm{CI}=.003 .216$ ). So, Orthodox followers are found to utilize health extension service as compared to Muslims and followers of other religion (e.g. Wake feta).

Knowledge of community on health extension service was one of the factors that affect community utilization of health extension service. Household respondents who have satisfactory knowledge on health extension service were 5.33 times more likely to utilize health extension services when compared to those who have unsatisfactory knowledge on health extension package/services $(\mathrm{OR}=5.33 ; 95 \% \mathrm{CI}=2.15$, 13.23). This result is consistent with studies conducted earlier $(23,24)$. This result is almost the same with the result conducted by Zewudu Kelbessa et al (2014) (37).

Limitation of this Study

1) The study was not incorporated focus group discussion that may enhance data obtained by quantitative study.

2) It was focused on HEP service utilization analysis but not attitude of study participants which might be another factor affecting the service utilization.

3) The study may be influenced by household recall bias on services like model graduation as it takes longer time.

\section{Conclusion}

Based on the information collected from 604 households who live in Merti Woreda Arsi Zone, Oromia Regional State, Ethiopia, the level of community utilization of health extension service and associated factors are identified. The 
level of community utilization of health extension service has registered relatively higher results as compared to the previous studies. Even though the health extension service is high, the implementation is found to be low in some packages such as women's immunization service, delivery, postnatal care service, community conversation, and model family. Similarly, in relation to model family graduation, the number of households that have been graduated is low. It is may be because of the limitation of the time provided to train households about the packages.

Age, educational status, religion, language, and knowledge about health extension service were identified as the independent factors affecting community health extension services utilization. The implication of this finding is that local governments and health authorities need to consider these variables when the development and implementation of health extension packages

\section{Recommendations}

1. The result shows that the implementations of some HEP packages are low. Implementation of the full packages of health extension program is needed. So, improvement mechanisms should be undertaken by Merti Woreda health office and other concerned bodies to boost the utilization of these packages.

2. It was also found that knowledge about health extension program is a determinant factor to the implementation of HEP. Therefore, the MOH, and other health development stakeholders working in the area should strengthen provision of information, education and communication to enhance their knowledge about HEP.

3. Some demographic factors also found to be the determinants for HEP. So, MOH should consider age, educational status, religion and language differences of the community during the planning and implementation of HEP.

4. Further studies should be undertaken to determine the level and factors affecting utilization of health extension service from the perspective of health extension workers on a wider scale.

\section{Acknowledgements}

We would like to thank Merti woreda Health office for collaboration during data collection. We would like to extend my foremost gratitude to Arsi university Public Health department for giving me the chance to conduct this thesis.

\section{References}

[1] FMOH Health sector strategic plan (HSDPIII); Planning and Programming A. A. Ethiopia. 2005.

[2] Note UB. August, 2015.

[3] FMOH. Health extension program in Ethiopia profile Health Extension and Education center June 2007.
[4] Yeshewalul. A. Evaluation of health service extension program in Ethiopia, Research presented to center for global health, Trinity college, Dublin University, Ireland. 2006.

[5] Assefa Admassiea A, H etl. "HIV/AIDS and the HealthRelated Millennium Development Goals: The Experience in Ethiopia." 2010; 369: 2112-311.

[6] PIP. Ethiopia's Health Extension Program: Addis Ababa, Ethiopia. 2008.

[7] FMOH. HSDP. 2012.

[8] $\mathrm{Al} \mathrm{Ke}$. Level of health extension service utilization and associated factors among community in AbunaGindeberet District. 2012.

[9] UNDP. Human Development Report. 2005.

[10] Nahumudin Kadir C, Feng Zoa, etl. Health Extension Workers in Ethiopia Improved Access and Coverage for the Rural Poor

[11] WHO Ua. Immunization: A Summary. 2007.

[12] Ethiopia WB. A Country Status Report on Health and Poverty. 2005; Volume II (28963-ET).

[13] CSA and Macro International. 2005.

[14] Health FMo. Ethiopia Community Based Newborn Care Implementation Guideline. December, 2012.

[15] Assefa G. Achieving the Health MDGs: Country Ownership in Four Steps. 2010: 1127-28.

[16] Uta $\mathrm{LaD}, \mathrm{S}$. The state of the evidence on program, activities, costs and impact on health outcomes of using Community Health Workers. 2007.

[17] Samuel Girma AGY, Yayehyirad Kitaw, etl. Human resource development in Ethiopia; Challenges of achieving the Millennium Development Goals. Ethiop. J. Health. 2007; 3: 216-31.

[18] Walker DaJ, S. How do we determine whether Community Health Workers are cost- effective. 2005; 3: 221-9.

[19] EDHS M. 2014.

[20] (FMOH). FMoH. Health Sector Strategic plan (HSDP-III) Draft, Planning and Programming Department. 2005c.

[21] Medhanyie A. The role of health extension workers in improving utilization of maternal health services in rural areas in Ethiopia. 2012.

[22] FMoH. Implementation Guidelines of Health Extension Program: Addis Ababa, Ethiopia. 2005.

[23] Hailu T. Household health extension package, challenges and implementation issues a lesson from field practice. 2005.

[24] FMoH. Report of the Joint Review Mission of HSDPIII. 2009.

[25] Diress Y. Assessment of practices of women during pregnancy and childbirth with the perspectives of HEW's role, Addis Ababa University, Addis Ababa, Ethiopia,. 2009.

[26] (CNHDE) CfNHDiE. Assessment of working conditions of the first batch of Health Extension Workers. 2006.

[27] Haile Negusse EMaMM. Initial community perspectives on the Health Service Extension Program in Welkait, Ethiopia. Hum Resour Health. 2007. 
[28] Walraven G WA. The role of traditional birth attend-ants with midwifery skills in the reduction of maternal mortality. 1999: 527-9.

[29] Awash Teklehaimanot Y, K., Asfawesen, G/Y., et al.;. Working Conditions of Health Extension Workers in Ethiopia. Ethiop. J. Health Dev. 2007: 246-59.

[30] Bhattacharyya K, Peter Winch, Karen LeBan. Community Health Worker Incentives and Disincentives: How They Affect Motivation, Retention, and Sustainability. 2001.
[31] FMoH. Health Sector Human Resource Development Framework. 2006-2010.

[32] Bryan Shaw AANPe. Determinants of Utilization of Health Extension Workers in the Context of Scale-Up of Integrated Community Case Management.

[33] Getachew Hailu. Assessment of the extent and determinants of functionality of health extension workers Addis Ababa University, Addis Ababa, Ethiopia. 2009. 